\title{
CHLOROPHYLL ESTIMATION OF LAKE WATER AND COASTAL WATER USING LANDSAT-8 AND SENTINEL-2A SATELLITE
}

\author{
S.Yadav ${ }^{1}$, Y.Yamashiki ${ }^{1}$, J.Susaki $^{2}$, Y.Yamashita $^{3}$, K.Ishikawa $^{4}$ \\ ${ }^{1}$ Graduate School of Advanced Integrated Studies on Human Survivability, Kyoto University, Kyoto 606-8501, Japan - \\ shwtdv@gmail.com *, yamashiki.yosuke.3u@kyoto-u.ac.jp \\ ${ }^{2}$ Department of Civil and Earth Resources Engineering, Graduate School of Engineering, Kyoto University, Kyoto 615-8540, Japan \\ - susaki.junichi.3r@kyoto-u.ac.jp \\ ${ }^{3}$ Kyoto University, Field Science Education and Research Center, Nagahama 625-0086, Japan - yoh@kais.kyoto-u.ac.jp \\ ${ }^{4}$ Lake Biwa Environmental Research Institute (LBERI), Otsu 520-0022, Japan - ishikawa-k@lberi.jp
}

\section{Commission III, WG III/10}

KEY WORDS: Chlorophyll-a, Landsat-8, Sentinel-2A, Coastal Water, Freshwater, Satellite-Remote Sensing

\begin{abstract}
:
Chlorophyll-a is an optically active compound (OAC) commonly used as a proxy for phytoplankton biomass in an aquatic environment. Retrieving the concentration of chlorophyll-a remains a challenge due to the presence of several OAC particularly in water bodies which are in proximity to the land-based activities. In this study, an effort has been made to estimate the chlorophyll-a concentration of both the freshwater Lake Biwa and the coastal water of Wakasa Bay in Japan. A spectral decomposition algorithm was used to determine the chlorophyll-a using the satellite images. The algorithm was applied to the satellite images from two different sensors namely Landsat-8 /OLI and Sentinel-2A/MSI. The satellite-derived chlorophyll-a concentration for the lake and coastal water from two different sensors were compared to assess the performance of both the sensors. The accuracy of the chlorophyll-a results derived from the images was evaluated with the in-situ measurement data of the chlorophyll-a for the Lake Biwa and the coastal water of Wakasa Bay. Both satellite sensors appear to give the best results for the coastal water $\left(\mathrm{R}^{2}>0.80\right)$ with an RMSE $<0.3 \mu \mathrm{g} / \mathrm{L}$. However, slight underestimation of chlorophyll-a noted for the Landsat-8 image with an increase in chlorophyll-a concentration. For the lake water, Sentinel-2A results were relatively better $\left(R^{2}>0.70\right)$ than Landsat- 8 , with an $R M S E$ of $<1.0 \mu \mathrm{g} / \mathrm{L}$. The obtained results will be useful to evaluate the primary productivity of both freshwater and coastal water body.
\end{abstract}

\section{INTRODUCTION}

\subsection{Background}

At large, global water bodies are classified into two, Case-1 and Case-2 water types. In the case-1 water, phytoplankton dominates the inherent optical properties (IOPs) of water (e.g., open ocean water). While Case- 2 water are the complex water bodies influenced by variety of optically active compound (OAC) such as phytoplankton, colored dissolved organic matter (CDOM), inorganic particles and other suspended matters (e.g., coastal and inland waters) ( Morel, 1988; Mobley et al., 2004; Matsushita et al., 2012). In the recent decade, the increased pollutant load degraded the water quality of case- 2 water mainly rivers, lakes and coastal oceans (Carpenter et al., 1998; Kändler et al., 2017; Zhang et al., 2018; Bhagowati and Ahamad, 2018). Land-based activities adjacent to the coastal and inland water bodies directly affect the water quality and aquatic ecosystem through numerous point sources (i.e., wastewater effluent, runoff from waste storages, stormwater outfalls) and non-pint sources of pollution (i.e., atmospheric deposition, agricultural runoff, deforestation and land conversion) (Fredston-Hermann et al. 2016; Kandler et al. 2017). Riverine transport is the primary mechanism for the direct impact of the terrestrial-human activities on the nearshore coastal waters and estuaries (Fredston-Hermann et al. 2016).

Excess sediment and nutrient transport from anthropogenic sources (e.g., agriculture, industries and sewage disposal) in case2 water often lead to increased turbidity and reduced light availability, which in turn negatively impacts the biogenic species in the aquatic environment such as fishes and corals in freshwater and coastal water (Silva et al., 2016; FredstonHermann et al., 2016; Lintern et al., 2017). Nutrient load to inland waters (Le et al., 2009; Yadav et al., 2017) and coastal zones (Cloern and Jassby, 2010) lead to eutrophication including harmful algal bloom. A most serious threat from eutrophication is hypoxia which is the decrease in the dissolved oxygen (DO) levels in bottom waters, created as planktonic algae decompose. Hypoxia occurs when DO falls below $2 \mathrm{ml}$ of $\mathrm{O}_{2} /$ liter, thus increased mortality of the benthic fauna (Diaz, 2009; Shulkin et al. 2012). Chlorophyll-a (Chl-a) an optically active compound $(\mathrm{OAC})$ and a proxy for phytoplankton biomass in an aquatic environment (Cullen, 1982; Blondeau-Patissier et al., 2014), is frequently used as a key indicator to describe the water quality, pollution effect and biophysical status of the water bodies (Carpenter et al., 1998; Shi et al. 2013; Cheng et al. 2013; Wozniak et al., 2014). Chlorophyll-a is the most common photosynthetically active pigment present in almost all phytoplankton species, which influences the optical properties of the freshwater and seawater by increasing the light backscattering with spectrally localized water-leaving radiance (BlondeauPatissier et al., 2014).

Remote sensing techniques which provide near-real-time synoptic overview of the large areas commonly used chlorophylla for monitoring the phytoplankton abundance in both inland water (Le et al., 2009; Cheng et al., 2013; Shi et al., 2013) and coastal waters (Reinart and Kutser, 2006; Le et al., 2013;

* S.Yadav 
Blondeau-Patissier et al., 2014; Wozniak et al., 2014). Algorithms that rely mostly on the detection of specific spectral features using blue, green, yellow, red or near-infrared (NIR) portion of the reflectance is well suited for discrimination of algal blooms from other naturally occurring phenomena. However, the reliability of the measured reflectance is often hampered by its sensitivity to such as the thickness of the floating algal layer, suspended particulates, bottom reflectance (in shallow water) and atmospheric corrections. Thus a satellite-based technique along with the knowledge of the study area aid in the accurate estimation of the phytoplankton abundance (Reinart and Kutser, 2006; Blondeau-Patissier et al., 2014).

Retrieving the concentration of chlorophyll-a using satelliteremote sensing remains a challenge not only due to the presence of several OAC but also of the available sensors specifications (Ha et al., 2017), particularly in water bodies which are in proximity to the land-based activities. Some studies showed that the broad wavelength spectral data available on current satellites (i.e., Landsat, SPOT) does not allow the estimation of chlorophyll-a in turbid water (Dekker and Peters, 1993; Ha et al., 2017). On the other hand, Sentinel-2A MSI with high spectral (13 bands) resolution considered highly suitable for monitoring chlorophyll-a in coastal and inland waters due to its red-edge band near $705 \mathrm{~nm}$ (band 5) and second peak of chlorophyll absorption in red band (665 nm, band 4) (Toming et al., 2016; Ha et al., 2017). In this study, an effort has been made to estimate the chlorophyll-a concentration of both the freshwater Lake Biwa and the coastal water of Wakasa Bay in Japan and the feasibility of two different sensors mainly Landsat-8 OLI and Sentinel-2A MSI were assessed and compared for both the water bodies. Furthermore, the applicability of the spectral decomposition technique was tested on both coastal and inland water body.

\subsection{Study Area}

The coastal water of Wakasa Bay (mainly Yura Estuary) and the Lake Biwa which is the largest freshwater lake in Japan was studied in this paper.

Lake Biwa $\left(35^{\circ} 20^{\prime} 59.48^{\prime \prime} \mathrm{N}\right.$ and $\left.136^{\circ} 10^{\prime} 33.16^{\prime \prime} \mathrm{E}\right)$ is located in the Honshu Island, southwest of Japan (Figure 1). The lake is an important freshwater source for over 14 million people in the Kansai region of Japan. The surface area of the lake is $670 \mathrm{~km}^{2}$ and a total catchment area of $3838 \mathrm{~km}^{2}$. The lake encompasses two basins, the north basin $\left(618 \mathrm{~km}^{2}\right)$ which is mesotrophic and deep (the mean and the maximum depths are $44 \mathrm{~m}$ and $104 \mathrm{~m}$, respectively), and the south basin $\left(52 \mathrm{~km}^{2}\right)$ which is eutrophic and shallow (the mean and the maximum depths are $3.5 \mathrm{~m}$ and 8 $\mathrm{m}$, respectively) (Yadav et al., 2017). Lake Biwa experienced eutrophication (mainly the south basin) during the economic growth period after the 1960s. The land use change in the catchment area is primarily attributed to the ongoing urbanization and change in the industrial structure in the periphery of the south basin, contributing to eutrophication. To curb the eutrophication and to restore the lake ecosystem, the Shiga Prefectural Government enacted the ordinance Prevention of Eutrophication of Lake Biwa in 1979 followed by the formulation of the Water Quality Conservation Plan in 1986. Consequently, water quality of the lake improved which led to an upsurge in the growth of submerged Macrophytes in the lake (Ishikawa et al., 2002; Yadav et al., 2017).

On the other hand, Wakasa Bay has a wide opening to the Japan Sea $\left(35^{\circ} 31^{\prime} 51.5^{\prime \prime} \mathrm{N}\right.$ and $\left.135^{\circ} 17^{\prime} 29.3^{\prime \prime} \mathrm{E}\right)$. Yura river which is one of the major river of the main island of Japan flows into the western part of the Wakasa Bay (Figure 1), also known as Tango sea. The river is $146 \mathrm{~km}$ in length and has a total catchment area of $1880 \mathrm{~km}^{2}$ with an annual discharge of $41 \mathrm{~m}^{3} \mathrm{~s}^{-1}$. The river discharge is high in the winter due to snow melting and low in summer. Besides, the area is also subjected to cyclonic rain depression in summer (Kasai et al., 2010). The Bay area generally has a steep topography near the continental shelf, except on the coast of Yura River where the sea bed inclination is gentle owing to the sediment deposition from the river. Coarse sandy bottom characterizes the shallow coastal area (3-5 $\mathrm{m})$ and fine sand at the coastal area of 10-20 m (Antonio et al., 2010). The Yura estuary is also classified as the microtidal estuary as the typical tidal range in the Yura estuary is $<0.5 \mathrm{~m}$ (Kasai et al., 2010).

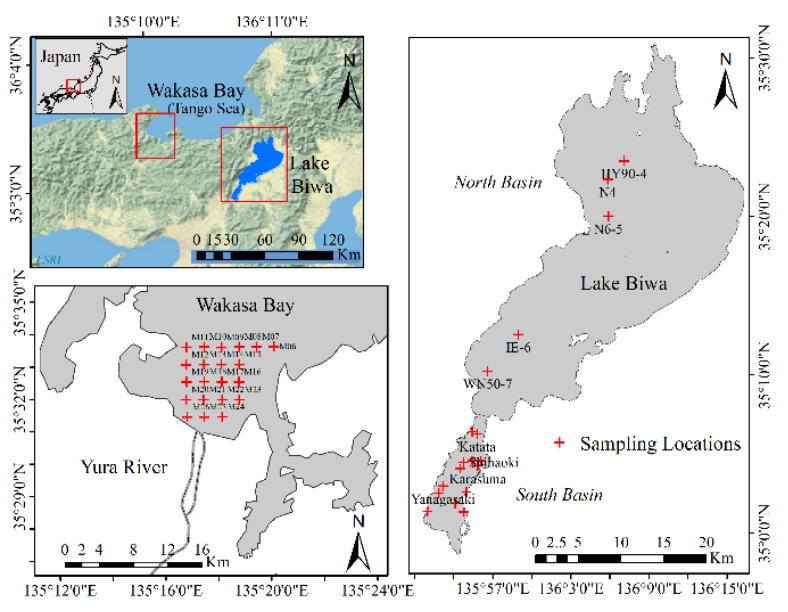

Figure 1. Geographical location of the freshwater lake (Lake Biwa) and coastal water (Wakasa Bay) in Japan.

\section{MATERIALS AND METHODS}

\subsection{Field Data}

The vertical profile of the chlorophyll-a, water temperature and many other parameters such as DO and turbidity were measured using the calibrated fluorometer (Chlorotech, ACL200 PDK, Alec Electronics) for Lake Biwa. The measurements were conducted together with Lake Biwa Environment Research Center (LBERI) between 31 July 2018 to 2 August 2018. Chlorophyll-a was measured for 18 locations. Water samples were collected from $0.3 \mathrm{~m}$ from the water surface for further measurements in the laboratory including phytoplankton species classification which is beyond the scope of this paper.

A vertical profile of the chlorophyll-a, salinity, water temperature and DO was measured at 21 locations in the Wakasa Bay (Yura Estuary) using CTD profiler (Compact CTD, Alec Electronics) and calibrated Rinko Chlorophyll Fluorometer. The water samples were taken from each location at $0.2-0.3 \mathrm{~m}$ from the surface. The filtered water samples (precombusted GF/F filters) were used for chlorophyll-a extraction using $90 \%$ acetone $(12 \mathrm{~h})$ which was then measured using the calibrated fluorometer. The data from the CTD profiler was then calibrated using the measured chlorophyll-a. The observations were carried out at every $1 \mathrm{~km}$ from the mouth of Yura Rivers. The spectral data at each location were measured using the ASD FieldSpec ${ }^{\mathrm{TM}}$ Pro JR Field Portable Spectroradiometer $(350-2500 \mathrm{~nm})$ and Handheld spectroradiometer (400-1100 nm). 
In addition, the reflectance characteristic of the aquatic vegetation species samples obtained by the diver survey were measured in the laboratory ASD FieldSpec ${ }^{\mathrm{TM}}$ Pro JR Field Portable Spectroradiometer and Handheld spectroradiometer (Yadav et al., 2017). Samples collected particularly from the south basin of Lake Biwa and the shorelines of the north basin, whereas in the Wakasa Bay samples collected from the two locations near the shallow coast of Yura River (3-5 m).

\subsection{Satellite Remote Sensing Data}

The Landsat-8 OLI image (30 m spatial resolution) and Sentinel2A MSI image (10, 20, $60 \mathrm{~m}$ spatial resolution) for Wakasa Bay and Lake Biwa were acquired U.S. Geological Survey (USGS) EarthExplorer (USGS, https://earthexplorer.usgs.gov/.). The satellite images were downloaded based on survey time, geographical extent and environmental conditions. The Landsat8 acquisition date was 3 August 2018 and for Sentinel-2A acquisition date was 4 August 2018. Image rectification and geoprocessing were achieved using ENVI 5.2 image analysis software and ArcMap 10.3.1. Apart from rescaling to top of atmosphere (TOA) reflectance, the images were atmospherically corrected using the mid-latitude summer atmospheric model and maritime aerosol model in the atmospheric correction module FLAASH of ENVI 5.2. Field measured spectral data was further used to validate the atmospheric correction of the images.

\subsection{Chlorophyll-a Estimation Algorithm}

Spectral Decomposition Algorithm was used to estimate the chlorophyll-a in the mainly Lake Biwa and Wakasa Bay. In this algorithm, the mixed reflectance spectra of a given pixel are conceptualized as a linear combination of potential endmembers substantially contributing to the pixel reflectance (Yadav et al., 2017). We assume that this algorithm which was previously being used only for the shallow lakes can be applied to other optically-complex case- 2 water bodies influenced by sediment and nutrient loads which also supports the growth of aquatic vegetation. The mixed-pixel reflectance in the Spectral Decomposition Algorithm is expressed as in Equation1:

$$
\begin{gathered}
R(\lambda)=a_{p} \times R_{p}(\lambda)+a_{n} \times R_{n}(\lambda)+a_{v} \times R_{v}(\lambda) \\
+a_{w} \times R_{W}(\lambda)
\end{gathered}
$$

Where, $a_{p}, a_{n}, a_{v}$ and $a_{w}$ symbolize the decomposition coefficients of phytoplankton, non- phytoplankton suspended solids (NPSS), submerged aquatic vegetation (SAV), and water, respectively. $R_{p}, R_{n}, R_{v}$ and $R_{w}$ represent the standard reflectance spectra of phytoplankton, NPSS, SAV, and water, respectively. The wavelength is expressed by $\lambda$ in the equation.

Four decomposition coefficients were estimated by applying Equation (1) to each of the Landsat- 8 bands, blue, green, red and NIR (i.e., band 2 to band 5). Similar spectral bands were used for Sentinel-2A image (i.e., band 2, 3, 4 and 8A) representing blue green, red and NIR. In Sentinel-2A, band $8 \mathrm{~A}$ has $20 \mathrm{~m}$ spatial resolution comparison to blue, green, red band with $10 \mathrm{~m}$ spatial resolution. Therefore, band $8 \mathrm{~A}$ of Sentinel-2A was resampled to $10 \mathrm{~m}$ resolution in ArcGIS before using it in the equation. In addition, the standard reflectance spectra of the endmembers were simulated using the Bio-Optical model (Yadav et al., 2017), shown in Equation 2. For aquatic vegetation standard reflectance was selected from the average reflectance of the mixture of the species measured in the laboratory. The vegetation cover assumed to be homogeneous. The details of the equation can be found in (Lee et al., 1998; Oyama et al., 2009).

$$
\begin{aligned}
r_{r s}=(0.070+0.16 & \left.u^{0.752}\right) u(1 \\
& -1.03 \\
& \times \operatorname{Exp}\left\{-\left[\frac{1}{\cos \theta_{W}}\right.\right. \\
& \left.+1.2(1+2.0 u)^{0.5}\right](a \\
& \left.\left.\left.+b_{b}\right) H\right\}\right) \\
& +0.31 \rho \\
& \times E x p\left\{-\left[\frac{1}{\cos \theta_{W}}\right.\right. \\
& \left.+1.1(1+4.9 u)^{0.5}\right](a \\
& \left.\left.+b_{b}\right) H\right\}
\end{aligned}
$$

where $r_{r s}$ is the subsurface reflectance, $a$ and $b_{b}$ are the total absorption and backscattering coefficient, respectively, contributed by the pure water, phytoplankton, NPSS, and cDOM in the water column. In addition, $\theta_{W}$ indicates the subsurface solar zenith angle, $H$ indicates the bottom depth $(\mathrm{m})$, and $r$ indicates the remote sensing reflectance of the shallow water. Whereas, $u$ can be expressed by $a$ and $b_{b}$.

Furthermore, the phytoplankton decomposition coefficient $a_{p}$ obtained by solving the four bands using Spectra Decomposition Algorithm was used as an independent variable to estimate the phytoplankton biomass. The regression model was developed using the $a_{p}$ and the natural logarithm of Chl-a ( $\ln (\mathrm{Chl}-\mathrm{a})$ )for both Landsat-8 and Sentinel-2A images as given in Equation 3:

$$
\ln (\text { Chla })=A+B \times a_{p}
$$

Where, $A$ and $B$ represents the regression coefficients in the equation. The chlorophyll-a was estimated for both Wakasa Bay and Lake Biwa using the above algorithm on Landsat- 8 and Sentinel-2A images. The results were compared with the in-situ measured data of chlorophyll-a for both the water bodies.

\section{RESULTS}

Chlorophyll-a for Lake Biwa and Wakasa Bay was determined by applying the algorithm to both Landsat -8 and Sentinel-2A image. The satellite-derived chlorophyll-a of both the sensors were compared and evaluated using the in-situ measured data.

\subsection{Lake Biwa Satellite-Derived Chlorophyll-a}

When compared with Landsat-8, the Lake Biwa chlorophyll-a derived from the Sentinel-2A gives a good fit $\left(\mathrm{R}^{2}=0.76\right)$ with the in-situ measured data. The downloaded images of the two satellite sensors has the difference of one day, therefore the estimated chlorophyll-a values were not significantly different in the two sensor images. The chlorophyll-a map generated using the Landsat-8 and Sentinel-2A is shown in Figure 2. In both sensors, the estimated chlorophyll-a in the south basin of Lake Biwa was relatively higher than the north basin. 

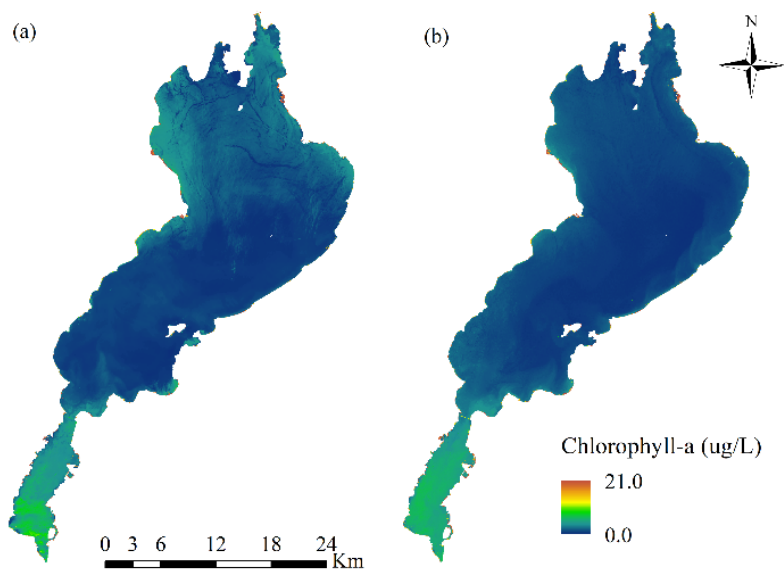

Figure 2. Estimated chlorophyll-a for Lake Biwa using two different satellite sensors: (a) Landsat-8 image and (b) Sentinel2A image for August 2018. (Note: ug/L represents microgram per liter).

Of 18 sampling locations in Lake Biwa, eight locations were used to validate the Landsat-8 and Sentinel-2A derived chlorophyll-a results. Sentinel-2A appears to give a good fit with the in-situ measured data as compared to Landsat- $8\left(\mathrm{R}^{2}=0.65\right)$. The observed chlorophyll-a and chlorophyll-a derived from Landsat8 and Sentinel-2A for Lake Biwa was evaluated as shown in Figure 3 and Figure 4, respectively.

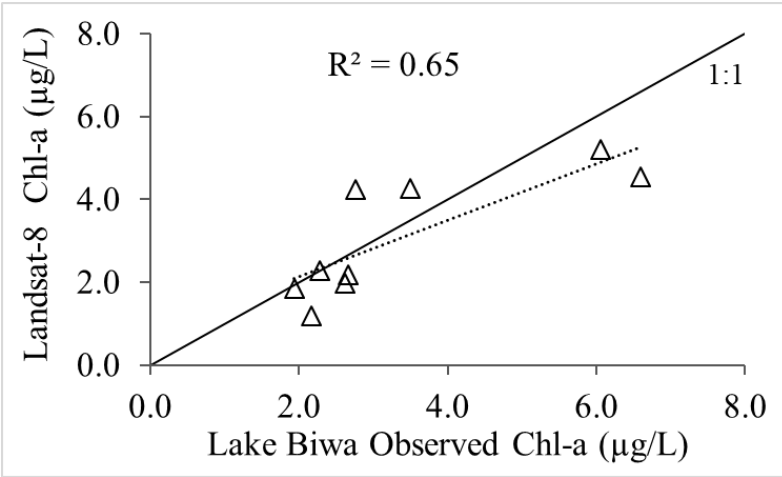

Figure 3. Observed and Landsat-8 derived chlorophyll-a for Lake Biwa (3 August 2018).

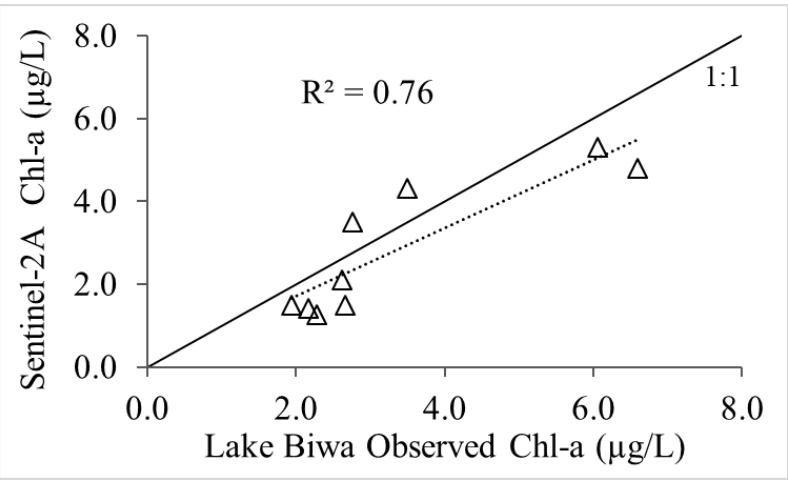

Figure 4. Observed and Sentinel-2A derived chlorophyll-a for Lake Biwa (4 August 2018).

With the increase in chlorophyll-a concentration both the sensors show slight underestimation. The maximum chlorophyll-a was noted near the shoreline of the south basin which is $21 \mu \mathrm{g} / \mathrm{L}$ by Landsat- 8 and $19 \mu \mathrm{g} / \mathrm{L}$ by Sentinel-2A. Based on the observed data, the root mean square error (RMSE) was estimated for both the sensors. The RMSE for the Sentinel-2A was $0.97 \mu \mathrm{g} / \mathrm{L}$ and Landsat- 8 was $1.02 \mu \mathrm{g} / \mathrm{L}$, as given in the Table 1 .

\begin{tabular}{ccccc}
\hline $\begin{array}{c}\text { Chlorophyll- } \\
\mathrm{a}(\mu \mathrm{g} / \mathrm{L})\end{array}$ & Observed & S-2A & L-8 & $\mathrm{N}$ \\
\hline Min & 1.9 & 1.3 & 1.2 & \\
Max & 6.6 & 5.3 & 5.2 & \\
Average & 3.4 & 2.9 & 3.1 & 8 \\
RMSE & & 0.97 & 1.02 & \\
\hline
\end{tabular}

Table 1. Accuracy assessment of satellite-derived chlorophyll-a in $\mu \mathrm{g} / \mathrm{L}$ for the Lake Biwa using in-situ data. (S-2A = Sentinel$2 \mathrm{~A} ; \mathrm{L}-8=$ Landsat- $8, \mathrm{~N}=$ number of validation points).

\subsection{Wakasa Bay Satellite-Derived Chlorophyll-a}

In Wakasa Bay, which receives the inflow from the Yura River, the maximum chlorophyll-a concentration estimated from the two sensors was $8.5 \mu \mathrm{g} / \mathrm{L}$, near the river mouth. The satellitederived chlorophyll-a using Landsat- 8 and Sentinel-2A is shown in Figure 5.
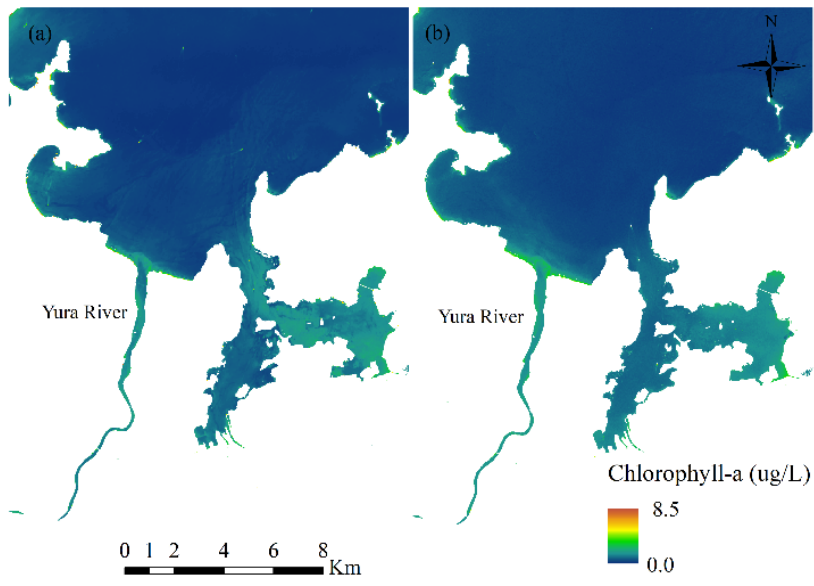

Figure 5. Estimated chlorophyll-a for Wakasa Bay coastal zone (Yura Estuary) using two different satellite sensors: (a) Landsat8 image and (b) Sentinel-2A image for August 2018. (Note: $\mathrm{ug} / \mathrm{L}$ represents microgram per liter).

No significant visible difference was observed between the satellite-derived chlorophyll-a of the two sensors. Of 21 sampling locations, 12 locations were used for the validation of the results from two satellite-sensors. Both sensors, appears to give the best result with $\mathrm{R}^{2}=0.81$ (Landsat- 8 ) and $\mathrm{R}^{2}=0.83$ (Sentinel-2A). The results of the chlorophyll-a derived from Landsat- 8 and Sentinel-2A for Wakasa Bay is shown in Figure 6 and Figure 7, respectively. 


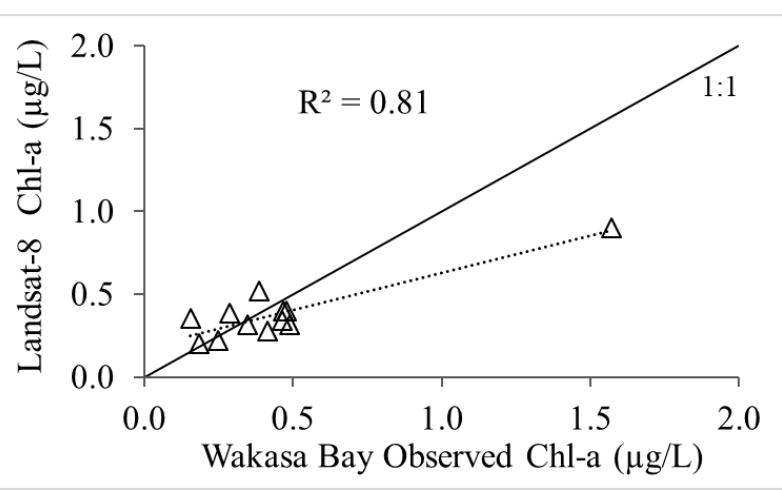

Figure 6. Observed and Landsat- 8 derived chlorophyll-a for Wakasa Bay (3 August 2018).

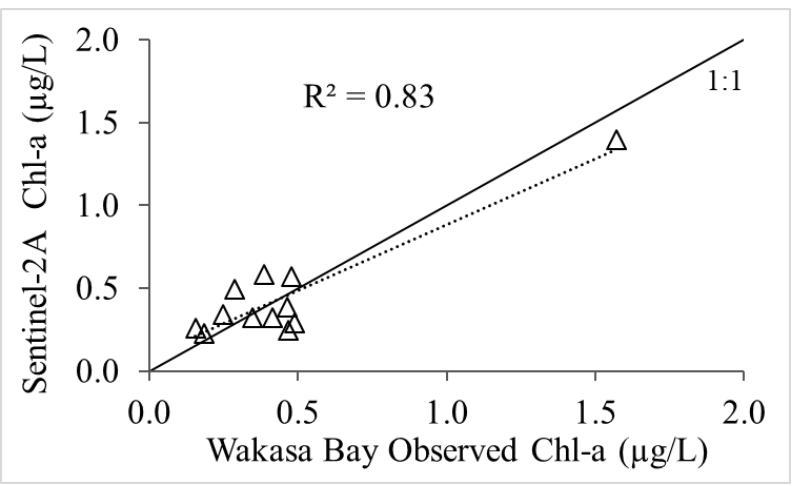

Figure 7. Observed and Sentinel-2A derived chlorophyll-a for Wakasa Bay (4 August 2018).

Although the results showed a good fit in Wakasa Bay, the underestimation of chlorophyll-a was observed particularly in the Landsat- 8 results with the increase in the chlorophyll-a concentration. The underestimation in the Landsat- 8 could be due to the differences in the spatial resolution. For instance, Landsat8 has $30 \mathrm{~m}$ resolution thus each pixel represents $900 \mathrm{~m}^{2}$ of the area however the estimated results were compared with the insitu measured point data of chlorophyll-a. Consequently, a slight difference in the results was obtained. Furthermore, Yura river is a major river inflow into the Wakasa Bay (Antonio et al., 2010). Thus, a possible difference in chlorophyll-a concentration due to the river flow was also expected in both the sensors. Obtained results for the Bay area indicates slightly better applicability of the Sentinel-2A for chlorophyll-a estimation. The RMSE calculated for the satellite-derived chlorophyll-a of Wakasa Bay is given in Table 2 .

\begin{tabular}{ccccc}
\hline $\begin{array}{c}\text { Chlorophyll-a } \\
(\mu \mathrm{g} / \mathrm{L})\end{array}$ & Observed & S-2A & L8 & $\mathrm{N}$ \\
\hline Min & 0.16 & 0.22 & 0.20 & \\
Max & 1.57 & 1.39 & 0.90 & \multirow{2}{*}{12} \\
Average & 0.46 & 0.45 & 0.39 & \\
\cline { 3 - 4 } RMSE & & 0.14 & 0.22 & \\
\hline
\end{tabular}

Table 2. Accuracy assessment of satellite-derived chlorophyll-a for the Wakasa Bay using in-situ data. (S-2A = Sentinel-2A; L-8 $=$ Landsat $-8, \mathrm{~N}=$ number of validation points).

\section{CONCLUSION}

In this study, efforts being made to test the suitability of the two different sensors Landsat-8 and Sentinel-2A for chlorophyll-a estimation in freshwater (Lake Biwa) and coastal water (Wakasa Bay - coast of Yura River). Moreover, the applicability of the Spectral Decomposition Algorithm to evaluate the chlorophyll concentration was also examined for coastal water along with the freshwater body. The algorithm was successfully applied to both the optically complex water bodies giving the root mean square error of $<2 \mu \mathrm{g} / \mathrm{L}$. Relatively higher chlorophyll-a concentration obtained through the satellite sensors for both the water bodies particularly near the shorelines and the river mouth (when compared with the inshore areas) also indicates the significant nutrient load through the river runoff and from the surrounding land use activities. A lower root mean square error $<1 \mu \mathrm{g} / \mathrm{L}$ suggests a better performance of Sentinel-2A for both the coastal and freshwater body than the Landsat- 8 . The medium resolution (i.e., $30 \mathrm{~m}$ ) of Landsat- 8 and discharge from the large river (in the coastal area) were suspected to be the cause of underestimation of the chlorophyll-a. Information of variation in climatic factors (i.e., rainfall) and river runoff are also essential as it could affect the water quality of a given water body.

\section{ACKNOWLEDGEMENTS}

This study is the part of the CoHHo project (Connectivity of Hills, Humans, and Oceans) supported by the Nippon Foundation. We are thankful for the help provided by Lake Biwa Environmental Research Institute (LBERI, Otsu) for data collection and laboratory support.

\section{REFERENCES}

Antonio, E.S., Kasai, A., Ueno, M., Won, N. il, Ishihi, Y., Yokoyama, H., Yamashita, Y., 2010. Spatial variation in organic matter utilization by benthic communities from Yura RiverEstuary to offshore of Tango Sea, Japan. Estuar. Coast. Shelf Sci. 86, 107-117. https://doi.org/10.1016/j.ecss.2009.10.020.

Bhagowati, B., Ahamad, K.U., 2018. A review on lake eutrophication dynamics and recent developments in lake modeling. Ecohydrol. Hydrobiol. https://doi.org/10.1016/j.ecohyd.2018.03.002.

Blondeau-Patissier, D., Gower, J.F.R., Dekker, A.G., Phinn, S.R., Brando, V.E., 2014. A review of ocean color remote sensing methods and statistical techniques for the detection, mapping and analysis of phytoplankton blooms in coastal and open oceans. Prog. Oceanogr. 123, 23-144. https://doi.org/10.1016/j.pocean.2013.12.008.

Carpenter, S.R., Caraco, N.F., Correll, D.L., Howarth, R.W., Sharpley, A.N., Smith, V.H., 1998. Vibrational spectra of crystalline n-paraffins. II. Intermolecular effects. Ecol. Appl. 8, 559-568. https://doi.org/10.1016/0022-2852(61)90347-2.

Cheng, C., Wei, Y., Sun, X., Zhou, Y., 2013. Estimation of chlorophyll-a concentration in Turbid Lake using spectral smoothing and derivative analysis. Int. J. Environ. Res. Public Health 10, 2979-2994. https://doi.org/10.3390/ijerph10072979.

Cloern, J.E., Jassby, A.D., 2010. Patterns and scales of phytoplankton variability in estuarine-coastal ecosystems. 
$\begin{array}{lll}\text { Estuaries } \quad \text { and } & \text { Coasts 33, 230-241. }\end{array}$

Cullen, J.J., 1982. The Deep Chlorophyll Maximum: Comparing Vertical Profiles of Chlorophyll a. Can. J. Fish. Aquat. Sci. 39, 791-803. https://doi.org/https://doi.org/10.1139/f82-108.

Dekker, A.G., Peters, S.W.M., 1993. The use of the Thematic Mapper for the analysis of eutrophic lakes: a case study in the Netherlands. Int. J. Remote Sens. 14, 799-821.

Diaz, R.J., 2009. Spreading Dead Zones and Consequences for Marine Ecosystems. Science (80) 926, 926-930. https://doi.org/10.1126/science.1156401.

Fredston-Hermann, A., Brown, C.J., Albert, S., Klein, C.J., Mangubhai, S., Nelson, J.L., Teneva, L., Wenger, A., Gaines, S.D., Halpern, B.S., 2016. Where Does River Runoff Matter for Coastal Marine Conservation? Front. Mar. Sci. 3, 1-10. https://doi.org/https://doi.org/10.1890/10510761(1998)008[055 9:NPOSWW]2.0.CO;2.

Ha, N.T.T., Thao, N.T.P., Koike, K., Nhuan, M.T., 2017. Selecting the Best Band Ratio to Estimate Chlorophyll-a Concentration in a Tropical Freshwater Lake Using Sentinel 2A Images from a Case Study of Lake Ba Be (Northern Vietnam). $\begin{array}{lllll}\text { ISPRS Int. J. Geo-Information } & 6,290\end{array}$ https://doi.org/10.3390/ijgi6090290.

Ishikawa, K., Kumagai, M., Vincent, W.F., Tsujimura, S., Nakahara, H., 2002. Transport and accumulation of bloomforming cyanobacteria in a large, mid-latitude lake: The gyreMicrocystis hypothesis. Limnology 3, 87-96. https://doi.org/10.1007/s102010200010.

Kändler, M., Blechinger, K., Seidler, C., Pavlů, V., Šanda, M., Dostál, T., Krása, J., Vitvar, T., Štich, M., 2017. Impact of land use on water quality in the upper Nisa catchment in the Czech Republic and in Germany. Sci. Total Environ. 586, 1316-1325. https://doi.org/10.1016/j.scitotenv.2016.10.221.

Kasai, A., Kurikawa, Y., Ueno, M., Robert, D., Yamashita, Y., 2010. Salt-wedge intrusion of seawater and its implication for phytoplankton dynamics in the Yura Estuary, Japan. Estuar. Coast. Shelf Sci. 86, 408-414. https://doi.org/10.1016/j.ecss.2009.06.001.

Le, C., Hu, C., Cannizzaro, J., English, D., Muller-Karger, F., Lee, Z., 2013. Evaluation of chlorophyll-a remote sensing algorithms for an optically complex estuary. Remote Sens. Environ. 129, 75-89. https://doi.org/10.1016/j.rse.2012.11.001.

Le, C., Li, Y., Zha, Y., Sun, D., Huang, C., Lu, H., 2009. A fourband semi-analytical model for estimating chlorophyll a in highly turbid lakes: The case of Taihu Lake, China. Remote Sens. Environ. 113, 1175-1182 https://doi.org/10.1016/j.rse.2009.02.005.

Lee, Z., Carder, K.L., Mobley, C.D., Steward, R.G., Patch, J.S., 1998. Hyperspectral remote sensing for shallow waters I A semianalytical model. Appl. Opt. 37, 6329. https://doi.org/10.1364/AO.37.006329.

Lintern, A., Webb, J.A., Ryu, D., Liu, S., Bende-Michl, U., Waters, D., Leahy, P., Wilson, P., Western, A.W., 2017. Key factors influencing differences in stream water quality across space. Wiley Interdiscip. Rev. Water 5, e1260. https://doi.org/10.1002/wat2.1260.

Matsushita, B., Yang, W., Chang, P., Yang, F., Fukushima, T., 2012. A simple method for distinguishing global Case-1 and Case-2 waters using SeaWiFS measurements. ISPRS J. Photogramm. Remote Sens. 69, 74-87. https://doi.org/10.1016/j.isprsjprs.2012.02.008.

Mobley, C., Stramski, D., Bissett, P., Boss, E., 2004. Optical Modeling of Ocean Waters: Is the Case 1 - Case 2 Classification Still Useful? Oceanography 17, 60-67. https://doi.org/10.5670/oceanog.2004.48.

Morel, A., 1988. Optical modeling of the upper ocean in relation to its biogenous matter content (case I waters). J. Geophys. Res. 93, 10749. https://doi.org/10.1029/JC093iC09p10749.

Oyama, Y., Matsushita, B., Fukushima, T., Matsushige, K., Imai, A., 2009. Application of spectral decomposition algorithm for mapping water quality in a turbid lake (Lake Kasumigaura, Japan) from Landsat TM data. ISPRS J. Photogramm. Remote Sens. 64, 73-85. https://doi.org/10.1016/j.isprsjprs.2008.04.005.

Reinart, A., Kutser, T., 2006. Comparison of different satellite sensors in detecting cyanobacterial bloom events in the Baltic Sea. Remote Sens. Environ. 102, 74-85. https://doi.org/10.1016/j.rse.2006.02.013.

Shi, K., Li, Y., Li, L., Lu, H., Song, K., Liu, Z., Xu, Y., Li, Z., 2013. Remote chlorophyll-a estimates for inland waters based on a cluster-based classification. Sci. Total Environ. 444, 1-15. https://doi.org/10.1016/j.scitotenv.2012.11.058.

Silva, S.V.S., Dias, A.H.C., Dutra, E.S., Pavanin, A.L., Morelli, S., Pereira, B.B., 2016. The impact of water pollution on fish species in southeast region of Goiás, Brazil. J. Toxicol. Environ. Health 79, 8-16. https://doi.org/https://doi.org/10.1080/15287394.2015.1099484.

Toming, K., Kutser, T., Laas, A., Sepp, M., Paavel, B., Nõges, T., 2016. First experiences in mapping lakewater quality parameters with sentinel-2 MSI imagery. Remote Sens. 8, 1-14. https://doi.org/10.3390/rs8080640.

USGS, n.d. United States Geological Survey (USGS) EarthExplorer [WWW Document]. URL https://earthexplorer.usgs.gov/.

Wozniak, M., Bradtke, K.M., Krezel, A., 2014. Comparison of satellite chlorophyll a algorithms for the Baltic Sea. J. Appl. $\begin{array}{llll}\text { Remote } & \text { Sens. } & 8 & \end{array}$ https://doi.org/10.1117/1.JRS.8.083605.

Yadav, S., Yoneda, M., Tamura, M., Susaki, J., Ishikawa, K., Yamashiki, Y., 2017. A satellite-based assessment of the distribution and biomass of submerged aquatic vegetation in the optically shallow basin of Lake Biwa. Remote Sens. 9, 966. https://doi.org/10.3390/rs9090966.

Zhang, L., Xu, E.G., Li, Y., Liu, H., Vidal-Dorsch, D.E., Giesy, J.P., 2018. Ecological risks posed by ammonia nitrogen (AN) and un-ionized ammonia $(\mathrm{NH}<\mathrm{inf}>3</ \mathrm{inf}>)$ in seven major river systems of China. Chemosphere 202. https://doi.org/10.1016/j.chemosphere.2018.03.098 